\title{
Prospective, controlled, multicentre study of loperamide in pregnancy
}

\author{
A Einarson $\mathrm{RN}^{1}, \mathrm{P}$ Mastroiacovo $\mathrm{MD}^{2}, \mathrm{~J}_{\text {Arnon }} \mathrm{PhD}^{3}, \mathrm{~A}$ Ornoy $\mathrm{MD}^{3}$, A Addis $\mathrm{PhMD}^{4}$, \\ $\mathrm{H}_{\text {Malm MD }}{ }^{5}$, G Koren MD FRCPC ${ }^{1}$
}

A Einarson, P Mastroiacovo, J Arnon, et al. Prospective, controlled, multicentre study of loperamide in pregnancy. Can J Gastroenterol 2000;14(3):185-187.

BACKGROUND: Loperamide is a synthetic piperidine derivative used for the treatment of both acute and chronic diarrhea. Little is known about its safety and risk in pregnancy. Human data are limited to one surveillance study of Michigan Medicaid patients, with 108 women exposed in the first trimester. In this study there were six major birth defects, three of which were cardiovascular anomalies.

OBJECTIVES: To determine whether loperamide use in pregnancy is associated with an increased risk of major malformations. The secondary end points were rates of minor malformations, spontaneous and therapeutic abortions, and premature births, and mean birth weights.

PATIENTS AND METHODS: Women counselled by five teratogen information centres on the safety and risk of loperamide in pregnancy were followed after delivery and compared with a similar group of women matched for age, smoking, alcohol and other exposures.

RESULTS: One hundred and five follow-ups were completed; 89 of the women were exposed to loperamide in the first trimester of pregnancy. There were no statistically significant differences between the study group and the control group in any of the end points that were analyzed. However, of women who took loperamide throughout their pregnancy, 21 of 105 had babies who were $200 \mathrm{~g}$ smaller than babies in the control group.

CONCLUSIONS: The results of this study suggest that the use of loperamide during pregnancy is not associated with an increased risk of major malformations.

Key Words: Diarrhea; Loperamide; Pregnancy

\section{Étude prospective, contrôlée, multicentrique sur le lopéramide durant la grossesse}

\begin{abstract}
HISTORIQUE : Le lopéramide est un dérivé synthétique de la pipéridine, utilisé pour le traitement de la diarrhée aiguë et chronique. On en connaît peu sur son innocuité et les risques qu'il pose durant la grossesse. Les données sur l'être humain se limitent à une étude épidémiologique chez des patients du Michigan inscrits au régime Medicaid, 108 femmes y ayant été exposées au cours de leur premier trimestre de grossesse. Lors de cette étude, on a dénombré six anomalies congénitales importantes, dont trois étaient de nature cardiovasculaire.

OBJECTIF : Déterminer si le lopéramide utilisé durant la grossesse est associé à un risque accru de malformations congénitales majeures. Les paramètres secondaires ont été les taux de malformations mineures, les avortements spontanés et thérapeutiques, les naissances prématurées et le poids moyen à la naissance.

PATIENTES ET MÉTHODES : Des femmes ayant reçu un counselling auprès de cinq centres d'information sur la tératogénécité et l'innocuité du lopéramide durant la grossesse et les risques qui y sont associés ont été suivies après leur accouchement et ont été comparées à un groupe semblable de femmes assorties selon l'âge, le tabagisme ou la consommation d'alcool et autres caractéristiques.

RÉSULTATS : Cent cinq suivis ont été complétés; 89 femmes ont été exposées au lopéramide au cours de leur premier trimestre de grossesse. Pour aucun des points analysés, on n'a noté de différences statistiquement significatives entre le groupe sous traitement actif et le groupe témoin. En revanche, parmi les femmes qui ont pris du lopéramide tout au long de grossesse, 21 sur 105 ont eu des bébés qui pesaient 200 grammes de moins. CONCLUSION : Les résultats de cette étude donnent à penser que l'utilisation du lopéramide durant la grossesse n'est pas associée à un risque accru de malformations majeures.
\end{abstract}


L operamide (Imodium, Janssen-Ortho Inc, North York, Ontario/McNeil Consumer Products, Guelph, Ontario) is a synthetic piperidine derivative used for the treatment of both acute and chronic diarrhea. It exerts its action via cholinergic, noncholinergic, opiate and nonopiate receptor-mediated mechanisms. After oral administration, little systemic absorption takes place. About $40 \%$ of a $2 \mathrm{mg}$ dose is excreted in the feces, with about $30 \%$ being unchanged drug. Reproductive studies performed in the rat and rabbit revealed no evidence of impaired fertility or harm to the fetus at dose levels up to 30-fold the therapeutic dose for humans. This drug is commonly used for both acute and chronic conditions, such as travellers' diarrhea and inflammatory bowel disease (1). There are limited human data available on the use of this drug in pregnancy.

In a surveillance study of Michigan Medicaid patients, 108 pregnant women were exposed to this drug during the first trimester. There were six major birth defects, three of which were cardiovascular abnormalities (2). Because of the limitations of this study, such data are not sufficient to counsel women on the safety and risk of this drug in pregnancy. Because at least $50 \%$ of pregnancies are unplanned, it is likely that this drug may be used in early pregnancy (3). Because of this paucity of information, we decided to carry out this study to ascertain further the risk and safety for women consuming this drug during pregnancy.

\section{PATIENTS AND METHODS}

The Motherisk Program is a counselling service for pregnant and lactating mothers, and their health professionals. Information about the safety or risk of drugs, chemicals, radiation and infectious diseases is given to approximately 35,000 callers per year. The other centres in Italy, Israel and Finland have similar services. The authors attempted to follow all the women who had called enquiring about the safety of this drug in pregnancy. All women who had used the drug during pregnancy and agreed to participate were included in the study, with no exclusions. Upon contacting these women, history of exposure and pregnancy outcome were obtained, as well as other end points of interest, with the aid of a structured questionnaire (4). Exposure history included medical indication for drug used, dosage, frequency of administration and timing of exposure. Outcomes were confirmed whenever possible by the child's primary care physician. The primary outcome of interest was the presence or absence of a major malformation. Major malformation was defined as the presence of an anomaly that has an adverse effect on either the function or social acceptability of the individual (5). Secondary outcomes of interest were spontaneous or therapeutic abortions, stillbirths, and presence or absence of a minor abnormality. Exposure was said to be during organogenesis if it occurred between the fourth and 14th week of gestation, when rates of $1 \%$ to $3 \%$ for major malformations, $10 \%$ to $15 \%$ for minor malformations and up to $15 \%$ for spontaneous abortions are expected. In addition to comparing mean birth weights between the study and control groups, birth weights were compared between the babies whose mothers took the drug for
TABLE 1

Pregnancy outcome

\begin{tabular}{lccl}
\hline Outcome & Case & Control & P \\
\hline Live births & $95 / 105$ & $94 / 105$ & 0.5 \\
Spontaneous abortions & $6 / 105$ & $9 / 105$ & 0.59 \\
Therapeutic abortions & $4 / 105$ & $2 / 105$ & 0.68 \\
Major malformations & $0 / 95$ & $1 / 94$ & 0.49 \\
Minor malformations & $3 / 95$ & $3 / 94$ & 0.62 \\
Birth weight, g (mean $\pm \mathrm{SD})$ & $3368 \pm 533$ & $3407 \pm 470$ & 0.68 \\
\hline
\end{tabular}

only a few days for an acute case of diarrhea and those who took the drug throughout the pregnancy for chronic bowel disease.

Each woman was matched to a subsequent woman who had either called the authors about loperamide but had not needed to use it, or a woman who had been exposed to cisapride (a nonteratogenic drug for gastrointestinal motility problems) (6). They were also matched for age, smoking and alcohol use. To assess the possibility of selection bias, women lost to follow-up were compared with those participating for age, parity, smoking and alcohol use. Outcome end points of interest were compared between the study and control groups with the Student's $t$ test, $\chi^{2}$ or the Fisher's exact test, whenever appropriate. These follow-up procedures were approved by The Hospital for Sick Children's Research Ethics Committees.

\section{RESULTS}

A total of 105 women from five centres were followed prospectively. There were 58 cases from Toronto, Ontario; 25 from Rome, Italy; 16 from Jerusalem, Israel; four from Milan, Italy; and two from Helsinki, Finland. Eighty-nine (85\%) women took loperamide during organogenesis, with 21 (20\%) taking it throughout their pregnancies. Indications for use were short term, for an acute case of diarrhea, or chronic, for bowel disease such as Crohn's disease or irritable bowel syndrome. The doses varied greatly, from 4 to $6 \mathrm{mg}$ in total, to 2 to $6 \mathrm{mg} /$ day throughout the pregnancy.

In the study group, there were 95 live births, four therapeutic abortions and six spontaneous abortions. There were no major malformations and three minor malformations reported. The malformations consisted of a heart murmur, a mild right pelviectasis (no symptoms) and a hypospadia (minor). The mean birth weight was $3368 \mathrm{~g}$ (Table 1).

A subanalysis comparing the women who took the drug throughout pregnancy for chronic bowel disease with the women who took only a few doses for acute diarrhea was performed; the mean birth weight was $3261 \mathrm{~g}$ among women who took the drug throughout their pregnancy compared with $3441 \mathrm{~g}$ in those who took the drug for acute diarrhea. However, this difference was not statistically significant, although in the chronic use group, half of the babies weighed less than $3000 \mathrm{~g}$ (11 of 21). There were no statistical differences in the preterm delivery rates between the acute users and chronic users - four of $74(5 \%)$ and two of $21(9 \%)$ ba- 
bies, respectively, were born before 36 weeks' gestation ( $\mathrm{Ta}$ ble 2).

In the control group, there were 94 live births, two therapeutic abortions and nine spontaneous abortions. There was a baby with Down's syndrome and one major malformation: cleft palate with cupped ears. There were three minor malformations: bilateral twisted feet (no surgery required), microfacelia and pulmonary stenosis. The mean birth weight was 3407 g. Comparison between the two groups (Table 2) found no statistical differences in pregnancy outcome, including spontaneous and therapeutic abortions, rates of major and minor malformations, and mean birth weights. Maternal characteristics were also compared among the study group, the control group and the group lost to follow-up; no differences were found.

\section{DISCUSSION}

This is the first prospective, controlled study of loperamide in pregnancy to date. The results do not support the findings in the previous study with the Michigan Medicaid patients (2). In that study, which was a surveillance study with no personal interviews of patients (108), six major malformations were found in the first trimester, three of which were cardiac anomalies, compared with our group, which found no major malformations in the first trimester. This illustrates the importance of prospective, controlled studies of exposures in pregnancy, which include history and other specifics, such as concurrent drug use, smoking and alcohol use. With that being the only report available before the present study, it is probable that women are advised not to take loperamide during pregnancy. This is reasonable, except that many women are not aware that they are pregnant when taking medications. A large number of the women who took the drug on an acute basis did not consider whether they were pregnant, with a substantial number reporting that they were on holiday in a foreign country. In previous studies and during the counselling process, women have informed us that they have had a therapeutic abortion of an otherwise wanted pregnancy based on fear of the consequences of the drug exposure on their fetus (7). We did not find an increase in the rates of preterm delivery, nor were the birth weights statistically significantly different, although the babies of chronic users were $200 \mathrm{~g}$ smaller than babies in the control group. However, this fact, in addition to the finding that half of the babies born to mothers who were exposed throughout the pregnancy
TABLE 2

Comparison of birth outcomes between chronic and acute users of loperamide

\begin{tabular}{lccc}
\hline & $\begin{array}{c}\text { Acute use } \\
(\mathbf{n = 7 4 )}\end{array}$ & $\begin{array}{c}\text { Chronic use } \\
(\mathbf{n = 2 1 )}\end{array}$ & $\mathbf{P}$ \\
\hline Preterm labour & 4 & 2 & 0.86 \\
Birth weight, g (mean $\pm \mathrm{SD})$ & $3441 \pm 544$ & $3261 \pm 693$ & 0.21 \\
\hline
\end{tabular}

weighed less than $3000 \mathrm{~g}$, supports the results, as in other studies, that women with chronic bowel disease have smaller babies and should be encouraged to treat their condition with the appropriate medication during pregnancy, without fear of harming their babies $(8,9)$.

\section{CONCLUSIONS}

This first prospective controlled study of loperamide in pregnancy of 105 cases, with 89 exposures in the first trimester, suggests that this drug does not increase the baseline risk of major malformations. However, an increase in teratogenic risk of some rare malformations cannot be ruled out.

ACKNOWLEDGEMENT: This study was supported by Janssen Pharmaceutica: Division of Janssen-Ortho Inc. We thank Linda Goldberg for her invaluable assistance in the data collection.

\section{REFERENCES}

1. Imodium Product Monograph. North York: Janssen Pharmaceuticals, 1993.

2. Briggs GC. Drugs in Pregnancy and Lactation, 5 th edn. Baltimore: Williams \& Wilkins, 1998:627-8.

3. Better news on population (Noticeboard). Lancet 1992;339:1600,

4. Koren G. Maternal Fetal Toxicology, 2nd edn. New York: Marcel Dekker, 1994:707-26.

5. Marden PM, Smith DW, McDonald MJ.Congenital anomalies in the newborn, including minor variations. J Pediatr 1964;64:357-71.

6. Bailey B, Addis A, Lee A, et al. Cisapride use in human pregnancy. A prospective multicentre controlled study. Dig Dis Sci 1997:42:1848-52.

7. Einarson A, Bailey B, Jung G, Spizziri D, Baille M, Koren G. Prospective controlled study of hydroxyzine and cetirizine in pregnancy. Ann Allergy Asthma Immunol 1997;78:183-6.

8. Diav-Citrin O, Park WH, Veerasuntharam G, et al. The safety of mesalamine in human pregnancy: A prospective cohort study. Gastroenterology 1998;114:23-8.

9. Habal FM, Hui G, Greenberg GR. Oral 5-aminosalicylic acid for inflammatory bowel disease in pregnancy. Safety and clinical course. Gastroenterology 1993;105:1057-60. 


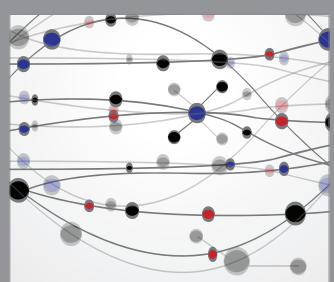

The Scientific World Journal
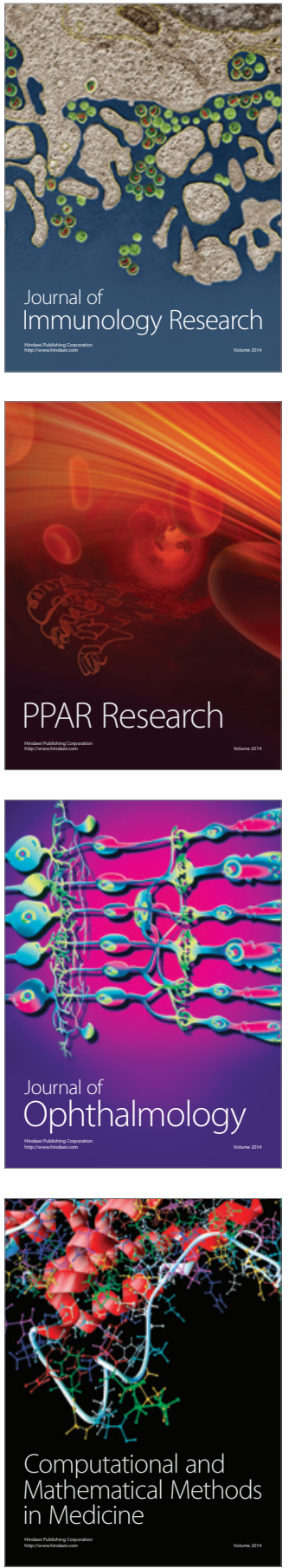

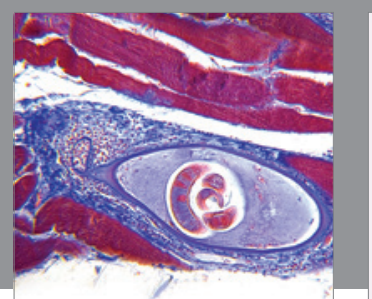

Gastroenterology Research and Practice

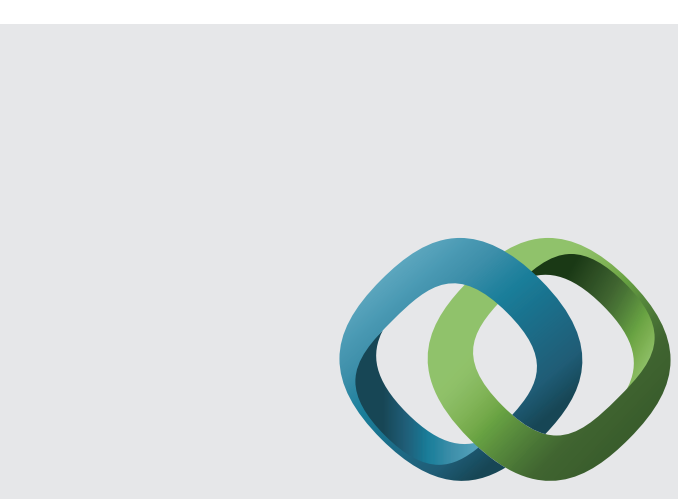

\section{Hindawi}

Submit your manuscripts at

http://www.hindawi.com
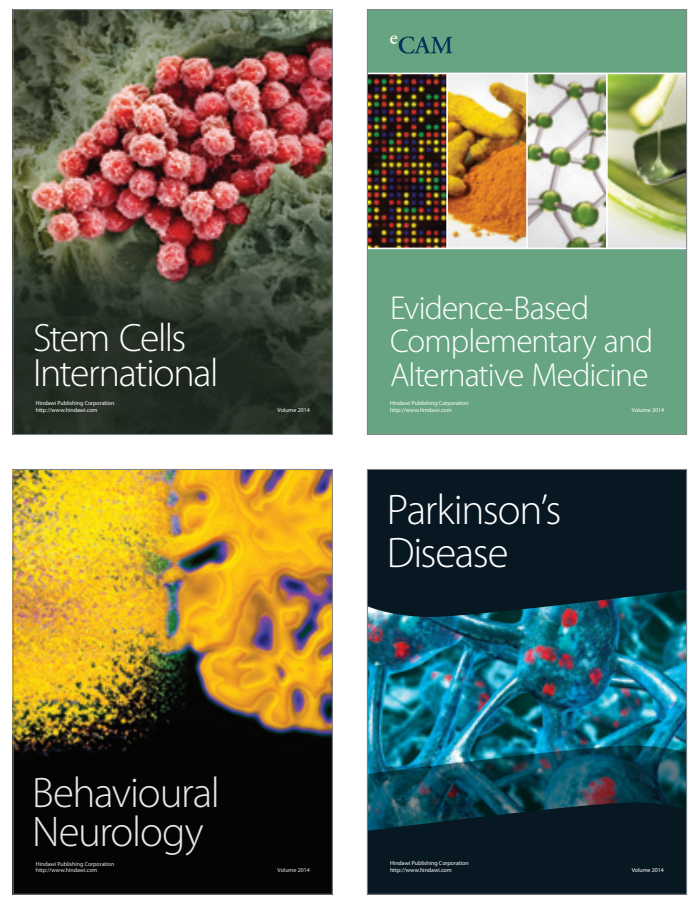
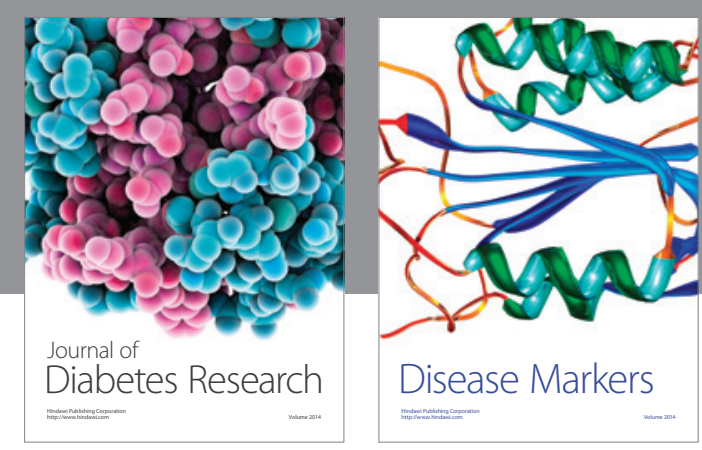

Disease Markers
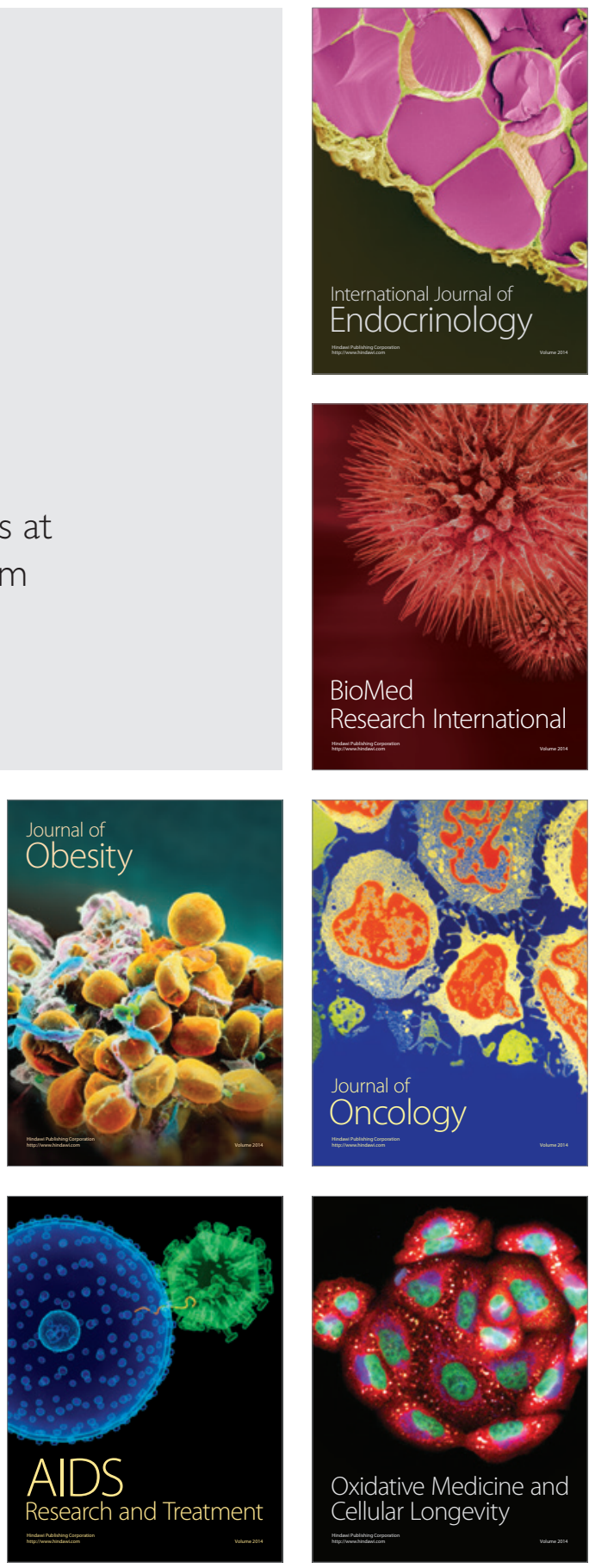